\title{
Safe and Sustainable Traditional Production: The Water Buffalo in Asia
}

\author{
Gautam K. Deb ${ }^{1 *}$, Talukder N. Nahar ${ }^{1}$, Peregrino G. Duran ${ }^{2}$ and Giorgio A. Presicce ${ }^{3}$ \\ ${ }^{1}$ Biotechnology Division, Bangladesh Livestock Research Institute, Dhaka, Bangladesh, ${ }^{2}$ Philippine Carabao Center, National \\ Head Quarters and Gene Pool, Science City of Muñoz, Philippines, ${ }^{3}$ ARSIAL - Centro Regionale per la Zootecnia, Rome, Italy
}

OPEN ACCESS

Edited by:

Chiara Frazzoli,

Istituto Superiore di Sanità, Italy

Reviewed by:

Maria Ines Zanoli Sato,

Companhia Ambiental do Estado de

Sao Paulo, Brazil

Ma Asuncion Guiang Beltran,

Tarlac Agricultural University,

Philippines

*Correspondence:

Gautam K. Deb

debgk2003@yahoo.com

Specialty section:

This article was submitted to

Environmental Health,

a section of the journal

Frontiers in Environmental Science

Received: 10 October 2015 Accepted: 02 May 2016 Published: 18 May 2016

Citation:

Deb GK, Nahar TN, Duran PG and

Presicce GA (2016) Safe and

Sustainable Traditional Production:

The Water Buffalo in Asia.

Front. Environ. Sci. 4:38.

doi: 10.3389/fenvs.2016.00038
The water buffalo (Bubalus bubalis) is considered an efficient converter of poor quality forages into high quality milk and meat. This species is ubiquitous, with prevalence though in Asian and Mediterranean countries. From a genetic standpoint, the species is characterized by two main subspecies: river and swamp type. The former to be found predominantly in Mediterranean countries, whereas the latter is found only in the Asia continent. At present, the majority of the total world buffalo population is distributed in Asia, holding around $97 \%$ of the available stock. There, animals are mostly fed on low quality roughages and crop residues with poor nutritive value, resulting inevitably in reduced productive and reproductive performances. A distinctive differential production system is in effect between river and swamp type buffaloes, due to a significant production capacity of the two sub-species. An overview of production systems and their sustainability in the two sub-species with an emphasis on country of origin and feed availability is presented.

Keywords: buffalo, Asia, production, sustainability, health

\section{INTRODUCTION}

The world population is growing at a fast rate and is expected to reach 8-9 billion by the end of 2030. Therefore, the advancement in a number of scientific and technological fields linked to animal production and related biotechnologies is mandatory. This will sustain not only the growing demand for food, but more importantly, will achieve a sustainable production methodology throughout the world and its different ecological areas, social and economic systems (Mehra, 2001; Pasha, 2013). In turn, a global and efficient sustainable system ensuring the availability of food for animal and human consumption, is reflected into the sustainability of each single enterprise, both for crop and animal production. In particular, in Asia the human population has grown dramatically, fuelled largely by a declining mortality linked to a better health system and improved living conditions. The growth in human population in Asia has also been accompanied by unprecedented economic growth that has allowed increases in income and purchasing power, and changes in food preferences (Cruz, 2007). These recent developments have major impacts on the demand for animal derived products, particularly meat and milk. In this framework, the buffalo, traditionally raised in a mixed crop livestock system, has played an important role over the centuries, and especially in Asia, for the lives of millions of people, by ensuring work power and food at the end of their career as work animals. The buffalo (Bubalus bubalis) is represented by two sub species: swamp and river, with a diploid chromosome number of 48 and 50, respectively. This animal is a major source of food (milk and meat), power, fuel, and by-products (hides, hoof, and bones), as well as manure to be used as fertilizer, especially in developing countries. Buffaloes are 
distributed worldwide, although the majority (around 97\%) of the total world buffalo population is present in Asia, where countries such as India, Pakistan, and China hold most of the available stock (Table 1). In these countries, animals are typically fed on "Low External-Input System" (FAO, 2011) based on lowquality roughages, like agricultural crop-residues/and industrial by-products containing high fibrous materials. In fact, differently from cattle and thanks to a better rumen fermentation (Wanapat et al., 2000) and nitrogen utilization (Devendra, 2007), buffaloes possess an intrinsic natural potentiality to strive and produce in hostile environments, thanks to their ability to efficiently utilize poor quality feed resources. Nevertheless, an improper feeding regimen and food availability inevitably impacts on reproductive and productive performances, by increasing mortality rates, delay in resumption of cyclicity, longer calving interval, and reduced growth rates (Qureshi et al., 2002; Tiwari et al., 2007; Sarwar et al., 2009; Pasha and Khan, 2010). In Asia, the river buffalo represents $\sim 75 \%$ of the total buffalo population mostly in South and West Asia, with the remaining 25\% represented by the swamp type found in South East Asia and South China (Borghese and Mazzi, 2005). According to the use made of these two subspecies across Asia, a different growth trend has been reported: (i) a positive trend in the buffalo population in milk producing countries of South Asia and (ii) a dramatic decline in many South East Asia countries where buffaloes are used mainly as draft animals. The entire population of buffaloes residing in Asia, is mostly raised by small hold farmers as an essential source of milk, meat and draft power, in a region where about $60 \%$ of the human population reside with an availability of roughly $33 \%$ of the Earth's arable land. Therefore, a major challenge for the future is to sustain the need for food of a fast growing human population, against the background of an ever decreasing unit area of arable land per person (Cruz, 2007). Although, the contribution of buffaloes to the zoo-economy of Asian countries has always been measured by the value of milk, meat, hide, and leather, it should be taken into account the hidden contribution, and its reflection in monetary terms, of this species as a source of draught power for the production of major crops such as rice, corn, sugarcane, and coconuts (Figures 1, 2).

TABLE 1 | Top 11 countries in Asia for buffalo population.

\begin{tabular}{lccc}
\hline Country & Buffalo heads & \% of the World & \% of Asia \\
\hline India & $110,000,000$ & 56.38 & 58.07 \\
Pakistan & $34,600,000$ & 17.73 & 18.27 \\
China & $23,779,811$ & 12.19 & 12.55 \\
Nepal & $5,178,612$ & 2.65 & 2.73 \\
Myanmar & $3,426,000$ & 1.76 & 1.81 \\
Philippines & $2,844,149$ & 1.46 & 1.50 \\
Viet Nam & $2,511,900$ & 1.29 & 1.33 \\
Bangladesh & $1,500,000$ & 0.77 & 0.79 \\
Indonesia & $1,320,600$ & 0.68 & 0.70 \\
Lao PDR & $1,153,000$ & 0.59 & 0.61 \\
Thailand & $1,020,088$ & 0.52 & 0.54
\end{tabular}

\section{ZOO-ECONOMICAL BACKGROUND}

The recent higher wealth and income in Asian countries, reflected by the increasing demands for food of animal origin, opposed to the declining land areas for agriculture and feed production, has brought an increasing trend in production and commercialization of swine and poultry. Poultry and swine production is more attractive to producers and investors due to a faster growth rate of the animals and commercialization of the end products, thanks also to the inherent efficiency advantage over ruminants in converting quality feedstuff into edible meat. This trend has inevitable implications on the importation of feed grains, which are typically not abundantly produced in the region. Therefore, the sustainability in Asian countries of food production from non-ruminant animals will be largely affected by the availability of feed grains in the international market, as well as the prevailing commodity and transport costs. In addition, the extent of possible conversion of grain to ethanol in Asian countries may have also significant impact in the years ahead. The rise in income among urban population has also brought about a corresponding shift in food preference as demonstrated by the increasing demand for beef and milk of ruminant origin. With the reduced land area for grazing and forage production, the only immediate option to meet the growing requirements is to increase the imports of milk and

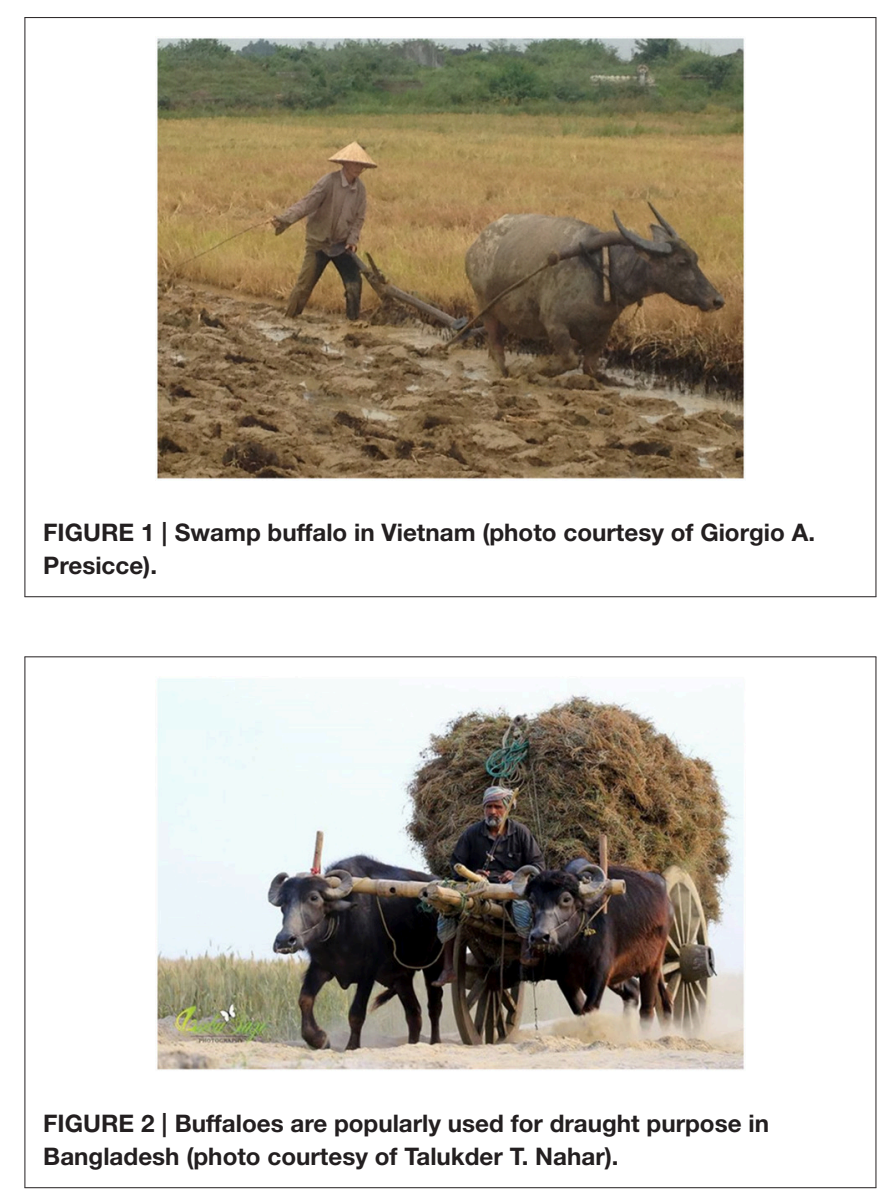


beef. As a long-term development strategy, however, efforts in fast-growing economies in Asia have also included programs to enhance growth in their respective local dairy industry, both cattle and buffalo, with massive infusion of dairy cattle stocks from Australia and New Zealand. This approach is evidently more meaningful in most of the Asian countries that still import large amounts of milk and dairy products. The reason has to be found in the skyrocketing of prices of milk in the international market due to (i) policy and regulatory measures in some exporting countries, and (ii) to unfavorable climatic factors, that have resulted in reduced production and reduced available and commercialized milk in the international market. In addition, the rising demand for dairy animals in order to restock farms in Europe and Latin America following BSE epidemic, has been coupled to the inevitable increase of prices for heads of dairy breeds. Most of the growth in the Asian region occurs in urban areas due to continued migration of people to the cities. This results in the formation of large concentration of consumers in urban communities, and consequently an increasing commercialization of various products in peri-urban areas. Commercial size livestock operations have created new challenges due to rising concerns on the resulting impact of increased waste and pollutants to the environment. Likewise, in view of the growing livestock production in the region, there is a heightened awareness on the need to achieve disease-free status to enhance trade in livestock and livestock products (Cruz, 2007).

\section{CONTRIBUTION OF BUFFALOES TO ASIAN ZOO-ECONOMY}

Riverine and swamp buffaloes co-exist in Asia, although the riverine type is typically seen in South and South-West Asia, whereas the swamp type is more characteristics and more easily found in East and South-East Asia. These two sub-species, as already anticipated, differ largely in terms of productivity and utilization within their respective geographical location. Such significantly different productive expectancy is reflected into the production system in which the two sub-species are positioned, respectively. The swamp buffalo is usually confined into a sort of mixed farming system within small-holder families, with a reduced number of buffaloes (1-5) per family, primarily used for draft purpose and meat at the end of their career as work animals. During the1990's, a dramatic decline in swamp buffalo heads was recorded, largely as a result of a massive farm mechanization and irrigation system in rice-producing areas where the swamp buffaloes are utilized primarily as source of draft power. Other countries in Southeast Asia, like Thailand, Myanmar, Vietnam, Indonesia, Cambodia have experience the same negative trend, coupled to a different positive trend in farm mechanization (Figure 3).

Swamp buffaloes though, still continue to be an important asset and tool for crop production and the sustenance of small families across Southeast Asia. This is so true that, some swamp type buffaloes like the carabao, found in the Philippines, have been part of an intensive effort lately in order to improve

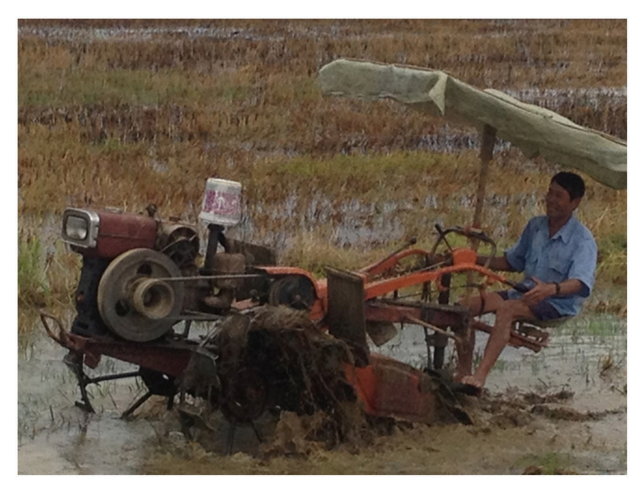

FIGURE 3 | Replacing swamp buffaloes with mechanization (photo courtesy of Giorgio A. Presicce).

their efficiency as work animals and, more importantly as milk and meat producers. A leading center in the Philippines, the Philippine Carabao Center (PCC) has been operating since 1993 for the improvement, propagation and promotion of the "Philippine Carabao." The efforts in such direction started much earlier though, since early 1900 until 1982, when the organization seed to become lately PCC, was the first and only at that time in Southeast Asian countries to use wide scale Artificial Insemination (AI) in water buffaloes. The PCC can be considered a leading example on how to steer energy and efforts to enhance the genetic potential of the swamp buffalo. A number of studies have been conducted in that direction. They have focused on farmer's capacity to improve the buffalo production management system and skill enhancement on dairy livestock, as well as to the acceptance, application and adoption of animal-related reproductive technologies, like AI, in vivo and in vitro embryo production, and cloning. In recent years, PCC has been participating in a number of international co-operations aiming at improving the overall productivity and exploitation of the carabao, by using the most recent technological advances for the improvement of management, reproduction, and production aspects in carabao farming. As an additional example of serious commitment to the carabao and its amelioration and preservation to become a superior swamp germplasm, the use of sexed semen has been taken into consideration and set in motion. This has been coordinated in further collaboration with Guangxi University, China (Goyagoy, 2011). Finally, as for other breeds of swamp buffaloes, the use of crossbreeding with river buffaloes is currently undergoing, in order to improve milk and meat producing capacity from F1 and F2 animals.

The river buffalo counterpart on the other hand, owing to its inherent higher milk productivity is being capitalized into emerging semi-commercial and commercial-size dairy operations around the peri-urban areas. Such buffalo farming is conducted in total confinement system, where animals are fed forages and other feedstuff produced in farms and then hauled to the dairy facilities. With regard to riverine buffaloes though, and despite their intrinsic higher productive potential, different systems of milk production are in effect across the 
countries where they are mostly stocked (India and Pakistan). As for swamp, riverine buffaloes mostly belong to a smallholder system, where animals are a strong asset in the family economy and production drive. At the village level, there are usually few animals per family, and in the majority of cases, produced milk is consumed within the family itself. This is due to the inherent difficulty to reach milk market centers and larger cities. Animals are fed by grazing them and completing their basic dietary requirements with supplemented straws, and when available a minimum of feed concentrates. Whenever there is a possibility to capitalize on milk production, then it is possible to assist in some sort of improved feeding and management practices involving a greater use of green fodder and to some extent feed concentrates. Finally, semi-commercial and commercial milk production setups can be seen around urban centers where milk plants are available. This more intensive system of milk production is a response to an ever increasing demand for milk in urban markets, involving also the promotion of forage production in order to sustain the increased energy requirements to the animals for higher milk production. Of course, as parallel development, animal wastes are also increased, posing in many cases possible pollution problems, due mainly to the inadequacy of waste management practices (Cruz, 2007).

Buffalo as a source of meat, has never been a primary productive goal anywhere in the world. Only at the end of their productive career, either as farming power or milk producers, buffaloes are sent to the slaughterhouse whenever they cannot be utilized anymore for their original purpose. This is true both at the village level as well as in an intensive farming system. Males, other than being essential in the buffalo farming system for reproductive purposes and for draft power, are considered more of a burden by the owner and are therefore culled even at young age, not reaching thus the full potentiality as meat producers. If an effort has to be envisaged by the owner, this will be capitalized rather than into males, into young females which later will be able to give birth and milk. An increasing trend is though observed in countries like India, where, due to socio-religious constraints and contrary to cattle, buffaloes can be used as meat producers. India is the country with the largest export of buffalo meat together with Pakistan toward the Middle East, to Australia and Hong Kong (Uriyapongson, 2013). A major effort is made in the most relevant countries in Asia in order to save unwanted males and capitalize them into meat production. In India, both private companies and governmental institutions are aiming at different strategies to rescue newborn males, which would otherwise be immediately culled, and including them into growing protocols up to $200 \mathrm{~kg}$ of live body weight before slaughtering. They are definitely winning strategies, as both farmers and companies have their share of return income (Dhanda, 2013). In addition, buffalo meat is the cheapest when compared to other meat producing species, and therefore a valuable source of protein for the "weaker part of society." It has to be underlined though that in Asia there is still a large room for improvement, considering that in many other countries such strategies adopted to invest in buffalo meat production are either not in place, or not commercially sustainable (Ranjhan, 2013). Other countries, like Italy where, despite the low number of heads, the degree of genetic selection on the riverine subspecies has reached possibly the highest potential, are trying to invest deeply on the exploitation of buffalo meat relying and focusing on the higher quality of the meat product when compared to the cattle counterpart. The significantly reduced fat content $(\approx 3 \%)$, which is deposited outside the muscle tissues, and a higher prevalence of unsaturated fatty acids as opposed to saturated fatty acid (differently of what is reported in cattle), makes the buffalo meat highly advisable for people who have difficulty in maintaining the correct blood cholesterol level. Finally, buffalo meat has a better water retention, making it softer and tasty when compared to other ruminant species, due to a reduced content of hydroxyproline, which is a component of collagen. Furthermore, recent scientific evidence reports a reduced risk of heart and circulatory problems in elderly people fed either buffalo or cattle meat (Infascelli et al., 2003). In any country, be it characterized by high or low level of wealth, such health issues could be instrumental for the development of a different approach toward the use of buffalo meat, and therefore the full exploitation of this species.

\section{IMPROVING THE BUFFALO}

In South and Southeast Asia, where most of the world buffalo population reside, the possibility to improve buffalo production as a whole, is linked to the exploitation and implementation of scientific advances and related technologies in some fundamental fields. Of course, there are countries in that part of the world, that will lead such path, due to their financial strength and input, and to their cultural approach to the improvement of living conditions. This general tendency in buffalo production traits will have to contend with the local and general sustainability of the entire process. The improvement in production of any trait (milk, meat, reproductive performance, etc.), is inevitably related to a number of genes and to environmental conditions. In the last decades, a tremendous improvement has been witnessed in the genome configuration of many animal species, following the publication of the human genome sequence in 2001, which represents a milestone in the understanding of similarity and differences among individuals in any animal population. Likewise cattle, a number of buffalo breeds have been sequenced, highlighting the identification of roughly 90,000 variants and single nucleotide polymorphism (SNP) in the buffalo genome. Such identified polymorphism in the buffalo population can be used to study the genetic "backbone" of the buffalo species, and to identify specific genetic variations which may have a significant impact on any production traits (Iamartino et al., 2013). Following SNP chips, epigenetic studies and microRNAs expression profiling in buffaloes, are helping in understanding the impact of gene diversity on economically significant traits and breeding strategies (Babar et al., 2013). Another area of strong interest for the improvement of buffalo productions, is nutrition. Of course there will always be areas in the Asian continent, where feeding buffaloes will be subjected and limited 
to local availability by relying mostly on crop residues. It's only within semi-intensive and intensive management systems, that feeding practices have relevance on their effect on productivity and environment. As for the latter effect, it is a well-known condition that livestock significantly contribute to greenhouse gas emission with regard to carbon dioxide, methane, and nitrous oxide (Steinfeld et al., 2006). Likewise cattle, in buffaloes too, strategies can be implemented in order to reduce methane emission and rumen methanogen bacteria by altering level of intake, frequency of feeding, type of feedstuff, ratio of forage to concentrate, type of carbohydrates, etc. (Boadi et al., 2004; Hook et al., 2010). Even natural compounds like tannins and saponins may help in tackling such task, by including them as feed additives thanks to their intrinsic anti-methanogenic activity (Beauchemin et al., 2008). As a result, converging from the above mentioned actions in buffalo management, "...manipulation of dietary fermentation and rumen enhancement would result in improved rumen fermentation end-products and reduced methane emission, thus enhancing productivity" (Wanapat and Kang, 2013). Lastly, a third approach to ameliorate buffalo productivity within its specific and diversified geographical domain and environmental constraints, is characterized by a global effort in enhancing reproductive efficiency through the application of newly developed reproductive technologies. It is well-known that buffaloes tend to be affected by a series of reproductive inefficiencies, as part of their physiologic condition, ranging from being tendentially seasonal as they move away from the equator, to delayed puberty and to long anestrus period, but on the other side being significantly longer-lived when compared to the cattle counterpart. Historically, in the early 80 's buffaloes were addresses for the very first time to check on their responsiveness following hormonal administration for follicle development and in vivo embryo development after AI (Drost et al., 1983). Unfortunately, to date, not much progress has been made using the same multiple ovulation and embryo transfer (MOET) approach (Presicce, 2007). Lately, buffaloes have increasingly been the subject of interest on which to apply the latest available technologies like in vitro embryo production, with a variable degree of success, but definitely making the buffalo a species of interest for that particular type of genetic exploitation (Gasparrini, 2002). As previously anticipated, the use of sexed semen has been tested in buffaloes, its feasibility has been proved both via $\mathrm{AI}$ and in vivo embryo production, as well as via in vitro embryo production (Liang et al., 2008; Lu et al., 2010), and the trend is now to have buffalo sexed semen commercially available worldwide. In Asian countries, where the swamp subspecies is predominant, there is a tendency to use semen from river buffaloes to crossbreed with swamp females, in order to have F1, F2, and backcrossing. Such crossbreeding offspring is characterized by a larger body size and higher milk and meat production ability when compared to the original swamp lines, together with a fertility not at all compromised. This is an additional strategy aiming at optimizing productive features typical of the river sub-species, while insisting in an environment with swamp predominance.

\section{BUFFALO DISEASES}

Buffaloes, like other domestic animals are exposed to parasitic infestations, microbial infections, toxic agents, and even dietary deficiencies (Hartung, 1994). Buffaloes are more or less susceptible to the same most common diseases and parasitic infestations observed in domestic cattle (Thomas, 2008). Clinical symptoms of most common buffalo diseases are very similar to cattle, and in general, buffaloes are more resistant to most of the diseases than domestic cattle. This feature favors the buffalo to survive in hot humid regions, which are usually conducive to diseases to a higher frequency. Therefore, in the same ecosystem, the effect of disease on buffalo and it's productivity is often less deleterious than on cattle. Variations in temperature, weather, rainfall, and sunshine in combination with seasonal shortages of feed and water could also influence the status of health and disease. Generally, animals with poor sanitary nutrition and health conditions are prone to be affected with diseases. Likewise other domestic farm animal species, newborn and young buffalo calves are less resistant to diseases than adult buffaloes. Therefore, calf mortality is the major cause of losses in the buffalo species. Calf pneumonia or diarrhea resulting from management, environmental, nutritional, and physiological variations, and various infectious and parasitic agents (Snodgrass et al., 1986), are the most important causes of buffalo calf mortality (Subasinghe, 1986; El-Ghari et al., 1994; Galiero et al., 1994; Islam et al., 2013). Second, most frequently observed calf disease is related to naval ill or joint affections. Naval pathologies occur frequently in calves born in unhygienic environment, with no disinfection treatment of the naval and at the same time receiving little colostrum (Radostits et al., 1994). Haemorrhagic septicaemia (HS) which is commonly known as pasteurellosis is the major threat to adult water buffaloes (Islam et al., 2013). This is caused by the bacterium Pasteurella multocida. Buffaloes are more susceptible to HS and die in larger number than cattle. Buffaloes though, are comparatively more resistant to many diseases including contagious bovine pleuro-pneumonia, foot root, foot and mouth disease (FMD), anthrax, black quarter, and mastitis, than cattle (Thomas, 2008). Incidence of mastitis is high in countries where high yielding buffaloes are kept for milk production. On the other end, buffaloes are comparatively less resistant to tuberculosis than cattle (Lall et al., 1969). Buffaloes are affected with tuberculosis when they are kept under unsanitary conditions. Sporadic outbreak of cowpox, rabies, tetanus, actino bacillosis, and ringworm in buffalo is also reported in many Asian countries, and regional variations are observed in the incidence of these buffalo diseases. For example, FMD incidence is rare in buffaloes in Egypt but is high in Myanmar and some islands of Indonesia. In India and Sri Lanka, the incidence of FMD is also low compared to cattle. In a recent study in Bangladesh, it was found that about $64.2 \%$ buffaloes rising at farmer's condition are infected with gastro-intestinal parasites. Parasitic load is also higher in young animals compared to adult buffaloes. It is comforting that tests, diagnostic procedures and treatment measures developed for domestic cattle can also be used efficiently in buffaloes (Thomas, 2008). A number of 
vaccines are available for the most common buffalo diseases. In most cases, buffalo diseases can effectively be controlled through proper vaccination and deworming at regular intervals.

\section{CONCLUSION}

Despite the significantly lower number of buffalo heads around the world, in comparison to cattle, they are going to still significantly impact more on Asian countries and their zoo-economies, against the continuous mechanization and introduction of dairy cattle heads. We are witnessing improved living conditions and health standards, leading to increased

\section{REFERENCES}

Babar, M. E., Hussain, T., and Wajid, A. (2013). Latest biotechnological approaches for efficient buffalo production. Buffalo Bull. 32, $142-150$.

Beauchemin, K. A., Kreuzer, M., O’Mara, F., and McAllister, T. A. (2008). Nutritional management for enteric methane abatement: a review. Aus. J. Exp. Agric. 48, 21-27. doi: 10.1071/EA07199

Boadi, D., Benchaar, C., Chiquette, J., and Masse, D. (2004). Mitigation strategies to reduce enteric methane emissions from dairy cows: update review. Can. J. Anim. Sci. 84, 319-335. doi: 10.4141/A03-109

Borghese, A., and Mazzi, M. (2005). "Buffalo population and strategies in the world," in Buffalo Production and Research, REU Technical Series, Vol. 67, ed A. Borghese (Rome: Food and Agricultural Organization), $1-39$.

Cruz, L. C. (2007). Trends in buffalo production in Asia. Ital. J. Anim. Sci. 6, 9-24. doi: 10.4081/ijas.2007.s2.9

Devendra, C. (2007). Perspectives on animal production systems in Asia. Livest. Sci. 106, 1-18. doi: 10.1016/j.livsci.2006.05.005

Dhanda, O. P. (2013). Changing dynamics in buffalo production systems in South Asian region. Buffalo Bull. 32, 311-317. Available online at: http://ibic.lib.ku.ac. th/e-Bulletin/32-sp1.pdf

Drost, M., Wright, J. M. Jr., Cripe, W. S., and Richter, A. R. (1983). Embryo transfer in water buffalo(Bubalus bubalis). Theriogenology 20, 579-584. doi: 10.1016/0093-691X(83)90082-1

El-Ghari, M. M., El-Rashidy, A. A., Mettias, K. N., Hassen, E. R., and Hassen, H. M. (1994). "Studieson neonatal diarrhea in buffalo calves," in World Buffalo Congress, Vol. 4 (São Paulo), 361-363.

FAO (2011). "Successes and failures with animal nutrition practices and technologies in developing countries," in Proceedings of the FAO Electronic Conference (Rome), 1-30.

Galiero, G., Consalvo, F., and Carullo, M. (1994). La criptosporidiosisneivitelli bufalini: unaggiornamento. Selezione Vet. 35, 449-453.

Gasparrini, B. (2002). In vitro embryo production in buffalo species: state of the art. Theriogenology 57, 237-256. doi: 10.1016/S0093-691X(01) 00669-0

Goyagoy, J. G. (2011). PCC takes steps on possible use of sexed semen for buffalo R\&D. PCC Newsletter 10, 4.

Hartung, J. (1994). "Environment and animal health" in Livestock Housing, eds C. M. Walter and D. Charles (Wallingford, UK: CAB International).

Hook, S. E., Wright, A.-D. G., and McBride, B. W. (2010). Methanogens: methane producers of the rumen and mitigation strategies. Archaea 2010:945785. doi: $10.1155 / 2010 / 945785$

Iamartino, D., Williams, J. L., Sonstegard, T., Reecy, J., Van Tassell, C., Nicolazzi, E. L., et al. (2013). The buffalo genome and the application of genomics in animal management and improvement. Buffalo Bull. 32, 151-158.

Infascelli, F., Cutrignelli, M. I., Bovera, F., Piccolo, G., Tudisco, R., Calabrò, S., et al. (2003). Nutritional characteristics of buffalo meat: Cholesterol content and fatty acid composition. Bubalus bubalis 4, 51-57. life expectancy, together with a gradual increase in Asian and world human population. Such inevitable facts urge us to ensure that efforts are properly addressed in various fields of scientific enquiry, in order to enhance buffalo production in a sustainable and holistic manner.

\section{AUTHOR CONTRIBUTIONS}

GD and GP designed the concept of this manuscript and subsequently drafted and finalized it for submission. TN and PD contributed in this manuscript through providing research information and revising it critically.

Islam, K. B. M., Alam, M. S., Nahar, T. N., and Taimur, M. J. F. A. (2013). "Development of preventionand control measures for different buffalo diseases," in Proceedings of the Annual Research Review Workshop-2013 of Bangladesh Livestock Research Institute (BLRI) (Dhaka).

Lall, J. M., Singh, G., and Gupta, B. R. (1969). Incidence of tuberculosis among cattle and buffaloesin India. Ind. J. Anim. Sci. 39, 51-58.

Liang, X. W., Lu, Y. Q., Chen, M. T., Zhang, X. F., Lu, S. S., Zhang, M., et al. (2008). In vitro embryo production in buffalo (Bubalus bubalis) using sexed sperm and oocytes from ovum pick up. Theriogenology 69, 822-826. doi: 10.1016/j.theriogenology.2007.11.021

Lu, Y., Zhang, M., Lu, S., Xu, D., Huang, W., Meng, B., et al. (2010). Sex-preselected buffalo(Bubalus bubalis) calves derived from artificial insemination with sexed sperm. Anim. Reprod. Sci. 119, 169-171. doi: 10.1016/j.anireprosci.2010. 01.001

Mehra, K. L. (2001). “Animal biotechnologies; benefits and concerns,” in National Workshop on conservation and management of genetic resources of livestock (NewDelhi: Natl. Acad. Agric. Sci.).

Pasha, T. N. (2013). Prospect of nutrition and feeding for sustainable buffalo production. Buffalo Bull. 32, 91-110.

Pasha, T. N., and Khan, E. U. (2010). "Buffalo milk production in Pakistan," in Proceedings of the 9th World Buffalo Congress (Buenos Aires), 222-230.

Presicce, G. A. (2007). Reproduction in the water buffalo. Reprod. Dom. Anim. 42, 24-32. doi: 10.1111/j.1439-0531.2007.00907.x

Qureshi, M. S., Habib, G., Samad, H. A., Siddiqui, M. M., Ahmad, N., and Syed, S. (2002). Reproduction-nutrition relationship in dairy buffaloes. I. Effect of intake of protein, energy and blood metabolites levels. Asian Aust. J. Anim. Sci. 15, 330-339. doi: 10.5713/ajas.2002.330

Radostits, O. M., Blood, D. C., and Gay, C. C. (1994). Veterinary Medicine- A Text Book of Diseasesof Cattle, Sheep, Pigs, Goats Horses, 8th Edn. London, UK: ELBS; Baillere Tindall.

Ranjhan, S. K. (2013). "Latest concepts in rearing buffaloes for meat production," in Proceedings The 10th World Buffalo Congress and the 7th Asian Buffalo Congress, 327-336.

Sarwar, M., Khan, M. A., Nisa, M., Bhatti, S. A., and Shahzad, M. A. (2009). Nutritional management for buffalo production. Asian Aust. J. Anim. Sci. 22, 1060-1068. doi: 10.5713/ajas.2009.r.09

Snodgrass, D. R., Terzolo, H. R., Sherwood, D., Campbell, I., Menzies, J. D., and Synge, B. A. (1986). Aetiology of diarrhoea in young calves. Vet. Record. 119, 31-34. doi: 10.1136/vr.119.2.31

Steinfeld, H. P., Gerber, T., Wassenaar, V., Castel, M., Rosales, M., and de Haan, C. (2006). Livestock's Long Shadow: Environmental Issues And Options. Rome: Food and Agriculture Organization (FAO), 390.

Subasinghe, D. H. A. (1986). "Calf mortality in buffaloes on major state farms in Sri Lanka (1970-74)," in Proceedings of the 5th Conference of the Institute of Tropical Veterinary Medicine (Kula Lumpur), 111-112.

Thomas, C. S. (2008). Efficient Dairy Buffalo Production. Tumba: DeLaval International $\mathrm{AB}$.

Tiwari, R., Sharma, M. C., and Singh, B. P. (2007). Buffalo calf health care in commercial dairy farms: a field study in Uttar Pradesh (India). Livest. Res. Rural Dev. 19, 38. Available online at: http://www.lrrd.org/lrrd19/3/tiwa19038.htm 
Uriyapongson, S. (2013). Buffalo and buffalo meat in Thailand. Buffalo Bull. 32, 329-332.

Wanapat, M., and Kang, S. (2013). World buffalo production: challenges in meat and milk production, and mitigation of methane emission. Buffalo Bull. 32, $1-21$.

Wanapat, M., Ngarmsang, A., Korkhuntot, S., Nontaso, N., Wachirapakorn, C., Beakes, C., et al. (2000). A comparative study on the rumen microbial population of cattle and swamp buffalo raised under traditional village conditions in the Northeast of Thailand. Asian Aust. J. Anim. Sci. 13, 918-921. doi: 10.5713/ajas. 2000.918
Conflict of Interest Statement: The authors declare that the research was conducted in the absence of any commercial or financial relationships that could be construed as a potential conflict of interest.

Copyright (c) 2016 Deb, Nahar, Duran and Presicce. This is an open-access article distributed under the terms of the Creative Commons Attribution License (CC $B Y)$. The use, distribution or reproduction in other forums is permitted, provided the original author(s) or licensor are credited and that the original publication in this journal is cited, in accordance with accepted academic practice. No use, distribution or reproduction is permitted which does not comply with these terms. 